\title{
SOME IMMEDIATE AND LONGER-TERM EFFECTS OF A ZOO EXHIBIT*
}

\section{R. DE YOUNG}
A. DOTZOUR
C. HOUSTON
G. MANUBAY
C. D. SAUNDERS

Antioch University New England, Keene, New Hampshire

\section{K. SCHULZ}

J. SMITH

University of Michigan, Ann Arbor

\begin{abstract}
Many people visit zoos each year to be entertained, restored, and educated. While the spotlight is usually on animals and habitats, zoos are increasingly focusing on humans and their role in environmental stewardship. The primate exhibit at Brookfield Zoo in Illinois was designed to address this new focus. The exhibit includes a multi-stage educational experience at its exit that highlights what visitors can do to incorporate conservation behavior into their lives. A feature of such an experience is the short time one spends in it. This article examines the effect of this brief educational exposure. The
\end{abstract}

*Based in part on a paper presented at the 31st Annual North American Association for Environmental Education Conference, Boston, Massachusetts.

(c) 2011, Baywood Publishing Co., Inc.

doi: 10.2190/ES.33.1.b

http://baywood.com 
findings indicate that the experience does increase interest among those behaviors that demand a considerable investment of time. While a follow-up survey revealed this interest diminished over time, the exhibit's core messages were resilient. This study provides evidence that even briefly experienced, free-choice educational exhibits can promote concern for environmental stewardship.

The American Zoo and Aquarium Association has challenged zoos to serve as conservation centers for their communities and to inspire visitors to adopt conservation behavior (Rabb \& Saunders, 2005). Zoos are meeting this challenge by developing holistic, ecosystem-based approaches that seek to change the public's environmental knowledge, skills, and behavior. Studies show that zoo visitors support these approaches (Andereck \& Caldwell,1994; Chicago Zoological Society \& Lincoln Park Zoological Society, 1993; Milan \& Wourms, 1992; Morgan \& Hodgkinson, 1996). Indeed, the visiting public considers environmental education to be a primary role of zoos and aquariums (Dierking, Burtnyk, Buchner, \& Falk, 2002; Mazur, 1993; Stoinski, Ogden, Gold, \& Maple, 1999) and a vast majority of visitors want to learn more about environmental stewardship, including specific conservation behaviors they can adopt (Dierking et al., 2002).

Learning while visiting a zoo is of particular interest to families with children (Andereck \& Caldwell, 1994), a group who are frequent zoo visitors (Chicago Zoological Society \& Lincoln Park Zoological Society, 1993). Because families with children are particularly receptive to educational interventions, an opportunity exists for zoos to increase environmental knowledge and encourage conservation behavior.

A variety of strategies exist for promoting conservation behavior throughout society (Vining \& Ebreo, 2002). These include long-term interventions in formal settings (e.g., classroom programs) and short-term informal experiences (e.g., visual prompts, public service announcements, educational exhibit) (Zelezny, 1999).

In practice, getting people to adopt conservation behavior has proven to be more difficult than originally supposed (De Young, 1993, 2000). It is suggested that to be more effective we should apply interventions repeatedly, at different societal levels (Allen \& Ferrand, 1999). Thus, it would seem particularly difficult to affect change using short-term experiences in informal settings.

The study reported here is an assessment of just such a short-term intervention in the informal setting of a zoo. Numerous studies suggest that zoos can positively influence visitors' environmental knowledge, attitudes, and behaviors (Dierking et al., 2002). To test this claim we examined whether a simple, briefly experienced, free-choice exhibit could encourage zoo visitors to become conservation-minded citizens (Saunders \& Stuart-Perry, 1997). The outcomes measured included visitors' intentions and behavior at different points in time: while at the zoo and several months later. 


\section{METHODS}

\section{Study Site}

Brookfield Zoo, just outside Chicago, includes exhibits designed to increase visitors' awareness of environmental issues and opportunities for conservation behavior. In 1998, Brookfield Zoo opened its Quest to Save the Earth (hereafter Quest), a permanent, three-season multi-stage exhibit that is unusual in not displaying any live animals and by focusing solely on human behavior.

Brookfield Zoo based the Quest on behavior change principles (Irvine, Foster, \& Saunders, 1995) and designed it as an optional exit experience to their Tropic World exhibit which itself focuses on the choices primates face in their effort to thrive. The Quest reinforces this theme by presenting a series of four challenges each about choices faced by visitors during a typical day. In the first challenge, visitors cross a Bog of Habits by selecting, one at a time, stones to step on (Figure 1). Each stone is inscribed with a different everyday behavior and, with the assistance of a guidebook and a spinner to randomize outcomes, visitors learn about the environmental consequences of their choices.

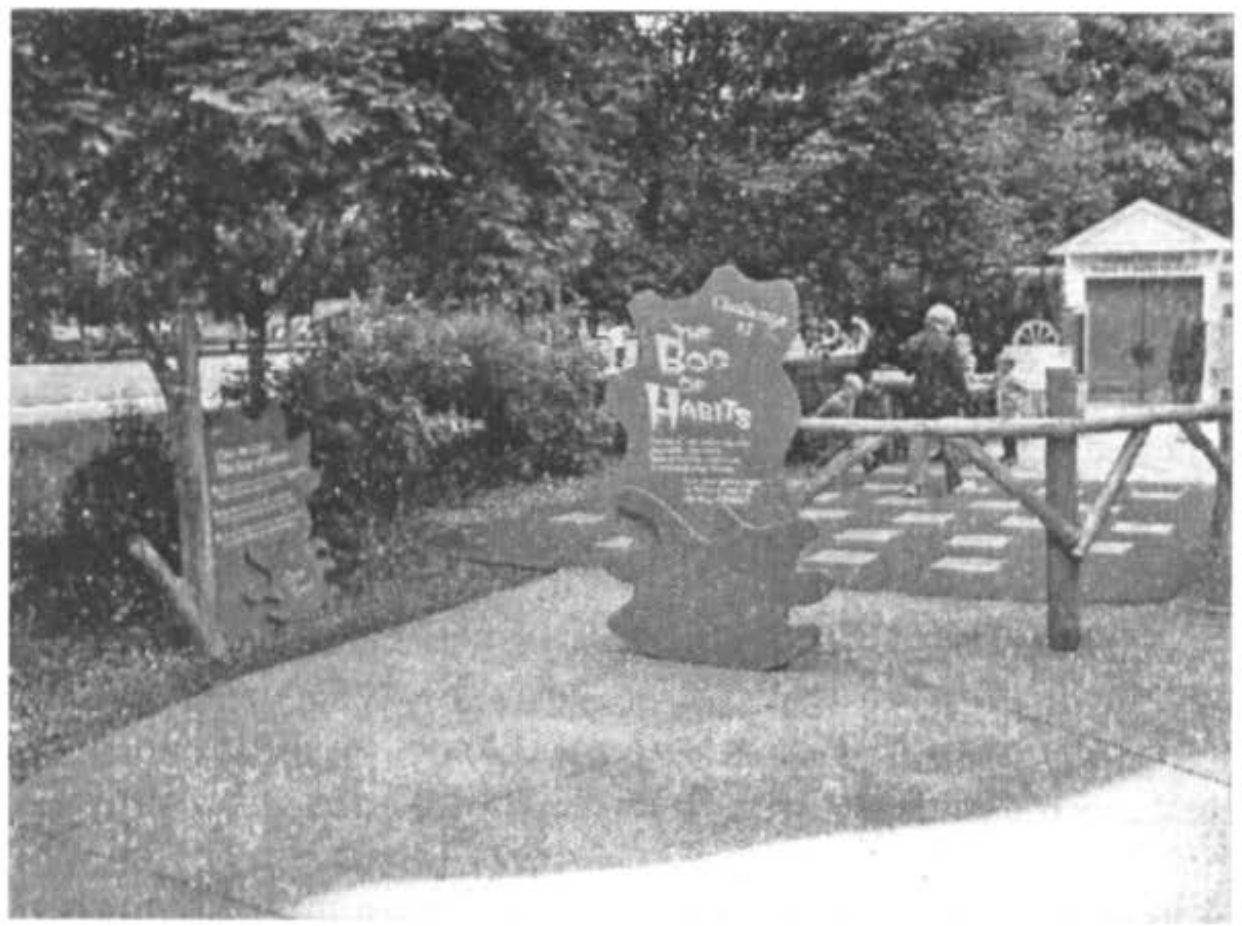

Figure 1. Bog of Habits. Stones identifying everyday behaviors are set in a soft recycled rubber bog. To cross this bog, visitors choose a sequence of behaviors while learning about resulting consequences. 


\section{Survey Instruments}

The two instruments used included an on-site survey and a follow-up survey. The goal of the on-site survey was to determine if playing the Bog of Habits affected visitors' intention to adopt conservation behavior. The instrument included banks of questions that focused on:

1. past participation in conservation behavior;

2. demographic characteristics of the survey respondents;

3. interest in performing particular behaviors in the future.

The latter section contained behaviors listed on the stones of the Bog of Habits as well as other environmentally responsible behaviors.

The follow-up survey was administered by telephone between 4 and 6 months after visitors had responded to the on-site survey. This instrument was designed to test the longer-term effects of playing the Bog of Hahits. It measured the salience of the messages contained within the Bog of Habits by including an open-ended question about what messages respondents recalled from their zoo visit. This question was framed in a general way and no mention was made of the Bog of Habits. Thus, the instrument assessed whether core messages within the Quest were memorable despite the passage of time and the fact that the Quest was but one small part of their zoo experience. The instrument also measured the persistence of the behavioral intentions that demonstrated a significant difference during analysis of the on-site survey data.

All analyses of survey data reported are significant at $p \leq .05$ unless noted.

\section{Participants}

Data were collected by a team of graduate students and zoo research assistants. Three hundred and fifty-five visitors participated in an on-site survey, 169 immediately after they played the Bog of Habits (called the Bog group) and 186 who indicated that they had not yet played the Bog of Habits nor had yet visited any other part of the Quest (called the Control group). The control group was contacted some distance away from the Quest and asked what exhibits they had visited that day or on previous trips. Only individuals who lacked prior experience with the Bog of Habits and Quest were surveyed.

Due to missing data, seven participants were excluded from the analysis, resulting in 164 surveys in the Bog group and 184 in the Control group. Of these initial participants, 55 were interviewed in the follow-up survey 4 to 6 months after their visit (Bog group $N=29$, Control group $N=26$ ).

No part of this study was designed as a true experiment since participants were not randomly assigned to the Bog and Control groups and thus self-selection by members of the Bog group might affect the results. However, analysis of the on-site survey data indicated that the Bog and Control groups differed in only a few ways. Respondents in the Bog group were slightly more likely to be zoo 
members $(p \leq .03)$, and among these zoo members, the Bog group had been members slightly longer than those in the control group $(p \leq .02)$. Visitors in the Bog group had visited the zoo more often during the past year $(p \leq .009)$. And groups who played the Bog of Habits tended to have children who were on average 2 years older than the children in the Control group $(p \leq .001)$. No differences were uncovered when analyzing the other background variables measured (i.e., education level, gender, exhibits visited, reason for visit, group size, group composition).

\section{Direct Action Study}

A small direct action study was developed to measure whether participants were more likely to go out of their way to seek additional information about conservation behavior as a result of visiting the Bog of Habits. All respondents to the on-site survey received a coupon redeemable for a brochure at a zoo information kiosk some distance from the Quest. These coupons were color-coded allowing return rates of the Bog and Control groups to be measured. It was explained to the participants that the brochure contained information about conservation behaviors that individuals and/or families could do at home to help the environment.

The direct action study also included a second phase which explored the possible effect of the on-site survey instrument on behavior. Although the on-site survey was completed by both the Bog and Control groups, it was relatively long and there was concern that it might somehow interact with the Bog group's Quest experience, differentially increasing the coupon redemption rate. To explore this possibility, the second phase involved a new sample of 51 zoo visitors (Bog group $N=30$, Control group $N=21$ ) collected as previously described. For this phase, a very short survey instrument was administered to this new sample and each respondent received the same coupon redeemable for the brochure. This survey instrument included only three attitude questions, three behavior questions, and a few background questions. No significant differences existed in coupon redemption rates for the two survey instrument designs, suggesting that the longer instrument was not interacting with the Quest experience to heighten redemption rates. Therefore, data from the two samples were combined for analysis of the direct action study (Combined sample: Bog group $N=194$, Control group $N=205$ ).

\section{RESULTS}

\section{Immediate Effects of the Bog of Habits}

Three categories of behavioral intentions emerged from factor analysis of the on-site survey items (principle axis factoring with Varimax rotation): behaviors that involved Simple conservation, those that would result in Energy conservation, and behaviors that were considered Time-intensive either to perform or to develop 
the competence needed to perform. Table 1 lists the items that made up each category, the overall sample mean, and the category reliability measure (Cronbach's alpha value).

These results suggest that, overall, respondents are more interested in pursuing simple actions than those that require a more significant investment of effort. For example, the relatively undemanding behaviors that comprise the Simple conservation and Energy conservation categories can be easily incorporated into one's daily life and performed on a regular basis. Furthermore, these behaviors are straightforward to complete, which can result in an immediate sense of accomplishment and competence. We speculate that the significantly lower mean for the Time-intensive conservation category reflects both the added complexity of these behaviors and perhaps a desire to first engage in simpler behaviors before making a commitment to adopt more complex activities.

A comparison of the Bog and Control groups revealed that while both groups reported similar levels of intention to perform simple behaviors, respondents who played the Bog of Habits reported a significantly higher intention to pursue the more time-intensive behaviors (Table 2). This suggests that the concepts

Table 1. Behavior Categories

\begin{tabular}{|c|c|c|c|}
\hline Category names and items included & Mean ${ }^{a}$ & $S D$ & Alpha \\
\hline $\begin{array}{l}\text { Simple conservation } \\
\text { Buy refills for cleaners or soaps } \\
\text { Pack lunch in a lunchbox } \\
\text { Take shorter, cooler showers } \\
\text { Buy locally grown vegetables }\end{array}$ & 4.08 & .91 & .67 \\
\hline $\begin{array}{l}\text { Energy conservation } \\
\text { Reduce the number of car errands I go on } \\
\text { Clean refrigerator coils } \\
\text { Line dry laundry }\end{array}$ & 3.59 & 1.05 & .51 \\
\hline $\begin{array}{l}\text { Time-intensive conservation } \\
\text { Compost food scraps } \\
\text { Write representatives in Congress } \\
\text { Volunteer for a conservation organization } \\
\text { Plant native plants in garden } \\
\text { Discuss Earth friendly behaviors with others } \\
\text { Buy sustainably harvested wood products } \\
\text { Donate money to help the environment }\end{array}$ & 3.04 & .86 & .81 \\
\hline
\end{tabular}


Table 2. Behavior Categories for Bog and Control Groups

\begin{tabular}{lcc}
\hline Category names & $\begin{array}{c}\text { Bog } \\
\text { group }\end{array}$ & $\begin{array}{c}\text { Control } \\
\text { group }\end{array}$ \\
\hline Simple conservation & 4.14 & 4.02 \\
Energy conservation & 3.69 & 3.49 \\
Time-intensive conservation & $3.23^{\mathrm{a}}$ & $2.87^{\mathrm{a}}$ \\
\hline
\end{tabular}

Note: Means sharing a superscript are significantly different from one another at $p \leq .001$.

encountered while playing the Bog of Habits motivated visitors to consider adopting somewhat more complex behaviors.

\section{Direct Action Study}

Because the on-site survey was a self-assessment, there existed the possibility that visitors' responses about their willingness to change behavior were overstated. To explore this possibility, a direct action study was conducted to determine whether participants would go out of their way to seek additional information about conservation behavior. All respondents to the on-site survey were given a coupon redeemable for a brochure about everyday conservation behaviors. This small test sought further evidence that playing the Bog of Habits had a positive effect, at least in the short-term.

The data indicate that respondents from the Bog group were over three times more likely to seek out the brochure's additional information on earth-friendly behaviors than were the Control group (redemption rates $11.3 \%$ and $3.4 \%$ respectively). This difference was statistically significant $\left(\chi^{2}=9.29, d f=1, p \leq .002\right)$. These data support the notion that playing the Bog of Habits increased visitors' interest in performing conservation behaviors. Furthermore, this finding suggests that even a short, voluntary experience is not only effective in encouraging higher levels of interest in performing time-intensive conservation behaviors, but may also motivate a next step toward such action.

\section{Rejecting a Competing Explanation}

The on-site survey revealed that the Bog group had significantly higher interest in performing time-intensive conservation behaviors than did the Control group. While this may have resulted from experiencing the Bog of Habits, one competing explanation to consider is self-selection. It is possible that visitors who 
went through the Bog of Habits did so because of an already higher level of interest in conservation behavior.

To explore this possibility, a follow-up survey was conducted. As shown in Table 3, when surveyed 4 and 6 months later, the Bog and Control groups were statistically identical in their interest to increase Time-intensive conservation behaviors. Furthermore, while the Bog group's level of interest decreased significantly between the on-site and follow-up surveys, the level of interest for the control group remained unchanged. This lack of persistence suggests that the previously reported difference between the two groups is less likely due to a pre-existing interest in time-intensive conservation behaviors by the Bog group and more likely an effect of the exhibit. Thus it seems reasonable to reject the alternate explanation.

\section{Longer-Term Effects of the Bog of Habits}

An intended outcome for the Quest is that "visitors will leave knowing they are making choices in their lives and that those choices have an impact on the health of the Earth" (Saunders, 1997).

The findings suggest that the messages of the Quest remained salient to the visitors. As the data in Table 4 suggest, as long as 6 months after visiting the zoo, $79 \%$ of the Bog group were able to describe the core messages of the Quest. One respondent captured in a brief statement the intent of the Quest exhibit, "one person can make a difference . . . everyday choices make a difference."

\section{CONCLUSION}

The findings reported here suggest that Brookfield Zoo's Bog of Habits, a brief, free-choice exhibit, has elements of a successful behavior change intervention. In the short-term, respondents who participated in the Bog of Habits reported higher levels of interest in time-intensive conservation behavior than did those who did not participate. These participants also were more likely to seek out additional information about everyday conservation behavior. Finally, it is encouraging to

Table 3. Interest in Time-Intensive Conservation Behaviors

\begin{tabular}{llc}
\hline & $\begin{array}{c}\text { Bog } \\
\text { group }\end{array}$ & $\begin{array}{c}\text { Control } \\
\text { group }\end{array}$ \\
\hline On-site survey (immediately after playing Bog of Habits) & $3.47^{a, b}$ & $2.95^{b}$ \\
Follow-up survey (4 to 6 months later) & $2.70^{a}$ & 2.61 \\
\hline
\end{tabular}

Note: Means sharing a superscript are significantly different from one another at $p \leq .05$. 
Table 4. How Often Bog Group Recalled the Questa

\begin{tabular}{lc}
\hline Key themes within positive responses & $\begin{array}{c}\text { Count of times } \\
\text { mentioned }^{b}\end{array}$ \\
\hline Things you can do to help the environment & 7 \\
Everyday choices can impact the Earth & 6 \\
Do your part and be more environmentally responsible & 4 \\
About environmental awareness & 4 \\
About environmental behaviors or concepts & 3 \\
Individuals can make a difference & 2 \\
\hline
\end{tabular}

${ }^{a}$ Of the 29 Bog group participants to the follow-up survey, $23(79 \%)$ could articulate core messages of the Quest.

${ }^{b}$ Responses with multi-part messages counted for multiple themes.

see that the exhibit's core concepts conveyed during the brief experience remain memorable months later.

Unfortunately, the interest in conservation behavior did not persist. However, we speculate that one way of encouraging persistent behavior change is to ease the restarting of a behavior that has lapsed. One possible condition necessary for the restarting of behavior may be to understand why it is important to pursue. If this conjecture proves accurate in future research, then one may discover that it's the persistence of core concepts, such as those conveyed by the Quest, that help participants to revive their interest after it has diminished.

Among the concerns of behavior change practitioners are whether voluntary educational experiences work at all, and when they do effect change, whether the effect is in any way durable. Given the number of environmental issues demanding attention, it is important that new messages both transfer to and then stay with us. This is true both for adults returning home from a zoo and children returning to the classroom after an educational outing. It is therefore heartening that the Bog of Habits was able to cause an increase in immediate interest and that its core messages remained salient.

\section{REFERENCES}

Allen, J. B., \& Ferrand, J. L. (1999). Environmental locus of control, sympathy, and proenvironmental behavior: A test of Geller's actively caring hypothesis. Behavior and Environment, 31, 338-353.

Andereck, K., \& Caldwell, L. (1994). Motive-based segmentation of a public zoological park market. Journal of Park and Recreation Administration, 12, 19-31.

Chicago Zoological Society \& Lincoln Park Zoological Society. (1993). Conservation related perceptions, attitudes, and behavior of adult visitors and non-visitors to 
Brookfield Zoo and Lincoln Park Zoo. Chicago, IL: Chicago Zoological Society and Lincoln Park Zoological Society.

De Young, R. (1993). Changing behavior and making it stick: The conceptualization and management of conservation behavior. Environment and Behavior, 25, 485-505.

De Young, R. (2000). Expanding and evaluating motives for environmentally responsible behavior. In L. Zelezny \& P. W. Schultz (Eds.), Promoting environmentalism. Journal of Social Issues, 56, 509-526.

Dierking, L. D., Burtnyk, K., Buchner, K. S., \& Falk, J. H. (2002). Visitor learning in zoos and aquariums: A literature review. Silver Spring, MD: American Zoo and Aquarium Association.

Irvine, K., Foster, S., \& Saunders, C. D. (1995). Using evaluation to guide the development of behavior change programs. Conference proceedings from the 1995 Visitor Studies Association on Theory, Research, and Practice, 8.

Mazur, N. (1993). Attitudes towards the role of city zoos in conservation: An Adelaide case study. International Association of Zoo Educators, 26-29.

Milan, L. M., \& Wourms, M. K. (1992). A zoological park is not just another museum. Curator, 35, 120-136.

Morgan, J., \& Hodgkinson, M. (1996). The motivation and social orientation of visitors attending a contemporary zoological park. Environment and Behavior, 31, 227-239.

Rabb, G. B, \& Saunders, C. D. (2005). The future of zoos and aquariums: Conservation and caring. International Zoo Yearbook, 39(1), 1-26.

Saunders, C. D. (1997). Interpretive plan for the Quest to Save the Earth. Unpublished manuscript. Brookfield, IL: Brookfield Zoo.

Saunders, C. D., \& Stuart-Perry, H. (1997). Summative evaluation of The Swamp: A conservation exhibit with a big idea. Visitor Behavior, 12, 4-7.

Stoinski, T., Ogden, J., Gold, K., \& Maple, T. (1999). The role of education in the conservation agenda of modern zoos. Proceedings of the Committing to Conservation Conference, San Diego Zoo, San Diego, CA.

Vining, J., \& Ebreo, A. (2002). Emerging theoretical and methodological perspectives on conservation behavior. In R. B. Bechtel \& A. Churchman (Eds.), Handbook of environmental psychology (pp. 541-558). New York: John Wiley \& Sons.

Zelezny, L. C. (1999). Educational interventions that improve environmental behaviors: A meta-analysis. Journal of Environmental Educational, 31, 5-14.

Direct reprint requests to:

R. De Young

School of Natural Resources and Environment

University of Michigan

440 Church Street

Ann Arbor, MI 48109-1041

e-mail: rdeyoung@umich.edu 